\title{
Genotype-independent Agrobacterium rhizogenes-mediated root transformation of chickpea: a rapid and efficient method for reverse genetics studies
}

\author{
Pooja Rani Aggarwal ${ }^{\dagger}$, Papri Nag ${ }^{\dagger}$, Pooja Choudhary, Niranjan Chakraborty and Subhra Chakraborty ${ }^{*}$
}

\begin{abstract}
Background: Chickpea (Cicer arietinum L.), an important legume crop is one of the major source of dietary protein. Developing an efficient and reproducible transformation method is imperative to expedite functional genomics studies in this crop. Here, we present an optimized and detailed procedure for Agrobacterium rhizogenes-mediated root transformation of chickpea.

Results: Transformation positive roots were obtained on selection medium after two weeks of A. rhizogenes inoculation. Expression of green fluorescent protein further confirmed the success of transformation. We demonstrate that our method adequately transforms chickpea roots at early developmental stage with high efficiency. In addition, root transformation was found to be genotype-independent and the efficacy of our protocol was highest in two (Annigiri and JG-62) of the seven tested chickpea genotypes. Next, we present the functional analysis of chickpea hairy roots by expressing Arabidopsis TRANSPARENT TESTA 2 (AtTT2) gene involved in proanthocyanidins biosynthesis. Overexpression of AtTT2 enhanced the level of proanthocyanidins in hairy roots that led to the decreased colonization of fungal pathogen, Fusarium oxysporum. Furthermore, the induction of transgenic roots does not affect functional studies involving infection of roots by fungal pathogen.

Conclusions: Transgenic roots expressing genes of interest will be useful in downstream functional characterization using reverse genetics studies. It requires 1 day to perform the root transformation protocol described in this study and the roots expressing transgene can be maintained for 3-4 weeks, providing sufficient time for further functional studies. Overall, the current methodology will greatly facilitate the functional genomics analyses of candidate genes in root-rhizosphere interaction in this recalcitrant but economically important legume crop.
\end{abstract}

Keywords: Legumes, Cicer arietinum, Agrobacterium rhizogenes, strain K599, Transformation efficiency, Functional genomics, Green fluorescent protein (GFP) expression, TRANSPARENT TESTA 2, Proanthocyanidins, Fungal infection

\section{Background}

The family Leguminosae is comprised of economically important legume crops, which are widely grown for grain and forage purposes [1]. The United Nations has declared 2016 as the 'International Year of Pulses', affirming the need to focus on the role that legumes can play in

\footnotetext{
*Correspondence: subhrac@hotmail.com

†Pooja Rani Aggarwal and Papri Nag contributed equally.

National Institute of Plant Genome Research, Aruna Asaf Ali Marg, New Delhi 110067, India
}

ensuring food security [2]. Chickpea (Cicer arietinum L.) is the second most widely grown pulse crop and serves as an important source of dietary protein [3]. It is cultivated for food and fodder in the semi-arid environment and poorly fertilized soil. Although chickpea is grown in more than 40 countries; South and Southeastern Asia are main growing regions, where India is the major contributor with approximately $67 \%$ of global annual production [4]. However, there has been stagnancy in chickpea 
production due to various biotic and abiotic stress factors $[5,6]$.

Similar to other legumes chickpea has a narrow genetic base which impacts its use in genetics and breeding for crop improvement. Despite the nutritional and commercial importance of chickpea, less is known about the pathways and genes responsible for agronomic traits because of its recalcitrant nature [7]. Recent efforts to sequence the expressed sequence tags (ESTs) $[8,9]$, transcriptome [10-12] and genome $[3,13]$ along with high-throughput proteome analyses [14-16] have led to the identification of novel genes, transcripts and proteins involved in several regulatory processes. However, tools for gene function analysis are very limited in chickpea. Determining the function of genes/proteins identified through various such large scale OMICS studies is a major challenge, especially in this recalcitrant crop for conventional transformation methods. An easy, reproducible and efficient method of plant transformation protocol is thus crucial for functional studies and crop improvement program. Introduction of new gene or modulation of the expression of an endogenous gene in a native system causes phenotypic variation that can be employed further for the elucidation of gene function. So far, few efforts have been made with standard Agrobacterium tumefaciensmediated transformation for developing transgenic chickpea [17-21]. However, the transformation efficiency achieved in these studies was very low, genotype dependent and the approach is laborious as well as time consuming. To circumvent these shortcomings, a rapid, efficient and genotype-independent transformation method is a pre-requisite for functional genomics studies in this important grain legume.

Root transformation using $A$. rhizogenes has emerged as an alternative to traditional transformation and breeding strategies that is gaining importance as an important tool for reverse genetics studies in plants, especially legumes [22]. Limpens et al. have shown that RNA interference in A. rhizogenes transformed roots also serve as a valuable approach in Arabidopsis and Medicago [23]. It is an efficient method of choice for quick over-expression or knock-out of genes in roots. The regenerated roots are also expected to be nonchimeric as they originate from single cells [24]. Recently, with the generation of disarmed A. rhizogenes, rol genes have been removed from the Ri plasmid which reduces the extent of undesirable hair-like root formation [25]. Owing to these advantages, regeneration of transgenic plantlets using A. rhizogenes has also been reported in several plants, including Nicotiana spp. [26], Ipomoea batatus [27], Brassica oleracea, Brassica campestris [28] and Spinacia oleracea [29].
Hairy root cultures have simplified the elucidation of root development and organ-specific response during root-pathogen and root-rhizosphere interactions. A key milestone among the wide applications of $A$. rhizogenes-mediated root transformation is the generation of composite plant consisting of transgenic root and wild-type shoot [30-32]. Composite plants serve as an ideal system for (1) studying root biology, (2) gene function studies in association with other organisms and (3) root-pathogen interaction studies. For example, pathogenicity of the soil-borne fungal pathogen Fusarium solani and the impact of isoflavanoid accumulation on pathogen invasion after hairy root development were studied in susceptible as well as partially resistant cultivars of soybean [33]. Similarly, propagation of cyst nematode in soybean [34,35], infection with mycorrhizal fungi in bindweed [36] and infection processes of obligate fungal parasites in strawberry [37] were studied by developing $A$. rhizogenes-mediated hairy roots. In addition, hairy root generation has been employed to study root and nodule development in alfalfa [38, 39], common bean [40], pea [41]; rhizobial colonization and nitrogen fixation in lotus [42, 43]. However, shoot evaluation using this method is only applicable where transgenic plants have been regenerated from $A$. rhizogenes-transformed hairy roots [26-29, 44]. In the past, $A$. rhizogenes-mediated root transformation has also been reported in chickpea $[45,46]$, however the efficiency of the method described in these studies was low with a variable degree of success (Additional file 1: Table S1).

Here, for the first time we report the method for $A$. rhizogenes-mediated highly efficient root transformation in different chickpea cultivars. Further, we demonstrate the expression of Arabidopsis MYB family transcription factor TRANSPARENT TESTA 2 (TT2) [47] in chickpea hairy roots that resulted in the massive accumulation of oligomeric proanthocyanidins (PAs). This method can be useful for large scale over-expression and knock-down studies of genes of interest in chickpea. In accordance, chickpea can be utilized as a model system to address important biological questions unique particularly to this legume crop and improving agronomic traits using our high-throughput root transformation method.

\section{Results and discussion}

Induction of hairy roots in chickpea using Agrobacterium rhizogenes

Agrobacterium rhizogenes-mediated root transformation in chickpea was performed following the protocol developed for Phaseolus with few modifications [40]. Prior to transformation, the binary vectors were 
transferred into competent $A$. rhizogenes strain K599 by electroporation as described earlier [48]. The suitability of K599 strain in the root transformation of legumes, including Glycine max [30] and Phaseolus spp. [40, 49] has been demonstrated previously. Transformation steps used for hairy root development are given in Fig. 1. Briefly, chickpea seeds were grown on MS salt medium ( $\mathrm{pH}$ 5.6). Five days old seedlings were used for

\footnotetext{
Sterilize the seeds and soak overnight in dark$$
\checkmark
$$

Place on germination media (pH 5.6)$$
5 \text { days }
$$

Section the root and immerse the cut end of roots in Agrobacterium suspension$$
\checkmark 35 \mathrm{~min}
$$

Incubation in co-cultivation media (pH 5.6) at $22^{\circ} \mathrm{C}$

$$
\downarrow 4 \text { days }
$$

Transfer on MS supplemented with antibiotic (pH 5.6) to induce transformed roots$$
\downarrow \text { About } 10 \text { days }
$$

Sub-culture and maintain the transformed roots in MS (pH 5.6)/transfer to pots

$$
\checkmark \text { About } 7 \text { days }
$$

Gene function investigation

Fig. 1 Schematic representation of the timeline required for Agrobacterium rhizogenes-mediated root transformation of Cicer arietinum
}

transformation. Preliminary experiments have revealed that transformation efficiency did not differ significantly for 5-7 days old seedlings. However, satisfactory results were not obtained beyond seventh day (data not shown). Roots were cut below epicotyl near the cotyledonary region and submerged into the suspension of A. rhizogenes $\mathrm{K} 599$ at optical density $\left(\mathrm{OD}_{600}\right)$ of 0.6. Slanting cut was made to increase the surface area for optimum bacterial contact. Alternatively, primary roots were also inoculated using cotyledonary injection method [40] and primary screening was performed by evaluating the number of explants with antibiotic selection positive roots. The efficiency of transformation on antibiotic selection medium was higher (73.33\%) using immersion method than the cotyledonary injection method (38.66\%) (Table 1). Therefore, immersion method of inoculation was used for subsequent studies and validation of the transformed roots.

In addition, both MS salt and water were used to resuspend the Agrobacterium and no significant difference was found in the root transformation efficiency (Table 2). It has been shown previously that induction of bacterial suspension with acetosyringone improves the transformation efficiencies and stability [50]. Both the bacterial media listed in Table 2 were supplemented with $100 \mu \mathrm{M}$ acetosyringone.

\section{Optimization of co-cultivation conditions}

After inoculation, seedlings were transferred to the cocultivation media. The marked effect of temperature and co-cultivation duration on transformation efficiency has previously been reported using both $A$. rhizogenes and A. tumefaciens [51-53]. We also optimized the co-cultivation temperature and duration to achieve maximum efficiency. For obtaining optimum conditions, various co-cultivation durations $(0.5,1,2,3,4$ and 5 days $)$ and temperatures $\left(20,22,24,26,28\right.$ and $\left.30{ }^{\circ} \mathrm{C}\right)$ were evaluated. Interestingly, transformation frequencies were found to be increased linearly from 0.5 to 3 days of cocultivation (12-71.33\%), exhibiting maximum efficiency at 4 days (74\%) (Fig. 2a). After 4 days, no significant

Table 1 Primary screening with different methods used for root transformation. Efficiency of two different methods used

\begin{tabular}{|c|c|c|}
\hline Method used for hairy root transformation by A. rhizogenes K599 & $\begin{array}{l}\text { Total number of explants } \\
\text { inoculated }\end{array}$ & $\begin{array}{l}\text { Explants with antibiotic } \\
\text { selection positive roots (\%) }\end{array}$ \\
\hline Infection through cotyledonary node injection in intact seedlings ${ }^{* *}$ & 50 & $38.66( \pm 3.05)^{b^{*}}$ \\
\hline Infection at the cut end of the hypocotyl ${ }^{* *}$ & 50 & $73.33( \pm 1.15)^{\mathrm{a}}$ \\
\hline
\end{tabular}
for root transformation of chickpea (Cicer arietinum cultivar Annigeri) seedlings

Each value represents the mean of three independent experiments with standard deviation (SD). Approximately 50 seedlings were examined for each individual experiment

* Values in the same column followed by different letters showed significant difference among different transformation methods (Fisher's LSD test, $P<0.05$ )

${ }^{*}$ Co-cultivation was done at $22^{\circ} \mathrm{C}$ for 4 days 
Table 2 Efficiency of root transformation of C. arietinum (cultivar Annigeri) with different bacterial suspension media

\begin{tabular}{lll}
\hline $\begin{array}{l}\text { Bacterial } \\
\text { suspension } \\
\text { media }\end{array}$ & $\begin{array}{l}\text { Total number } \\
\text { of explants } \\
\text { inoculated }\end{array}$ & $\begin{array}{l}\text { Explants with antibiotic } \\
\text { selection positive roots } \\
(\%)\end{array}$ \\
\hline MS salt $^{* *}$ & 50 & $72.50( \pm 2.5)^{\mathrm{a}^{*}}$ \\
Water $^{* *}$ & 50 & $73.33( \pm 3.8)^{\mathrm{a}}$ \\
\hline
\end{tabular}

Each value represents the mean of three independent experiments with standard deviation (SD). Approximately 50 seedlings were examined for each individual experiment

* Values in the same column followed by same letter showed no significant difference among different suspension medium (Fisher's LSD test, $P<0.05$ )

** Co-cultivation was done at $22{ }^{\circ} \mathrm{C}$ for 4 days

difference was observed in the efficiency. Next, we observed a slight increase in the transformation efficiency from $20{ }^{\circ} \mathrm{C}(73.3 \%)$ to $22{ }^{\circ} \mathrm{C}(74 \%)$. Root transformation efficiencies were decreased from 74 to $14 \%$ with the increasing temperature beyond $22{ }^{\circ} \mathrm{C}$ up to $30{ }^{\circ} \mathrm{C}$ (Fig. 2b). It is interesting to note that $22^{\circ} \mathrm{C}$ was reported as the optimum co-cultivation temperature in Lotus exhibiting $93.59 \%$ transformation frequency during $A$. rhizogenes-mediated root transformation [54]. Based on these observations, co-cultivation at $22{ }^{\circ} \mathrm{C}$ for 4 days was found to be optimum for chickpea root transformation. Subsequently, the seedlings were transferred to medium supplemented with $20 \mathrm{mg} \mathrm{L}^{-1}$ hygromycin and placed in light. Roots started emerging after 5-6 days of inoculation. The stages mentioned above are shown in Fig. 3a-i. In contrast, no roots were developed from the control plants inoculated with water on media supplemented with $20 \mathrm{mg} \mathrm{L}^{-1}$ hygromycin (Additional file 2: Fig. S1).

For comparative studies in transformed and untransformed roots, control plants treated with water were grown on medium without any antibiotic while transformed plants were grown on medium containing antibiotic. Two week post inoculation, plantlets were transferred to the pots and grown in the growth chamber (Fig. 3j). Roots grown outside an aseptic environment without selection showed increased lateral branching at three weeks post inoculation as shown in Fig. 3k.

\section{Selection of transformed hairy roots by GFP}

Green fluorescent protein (GFP) expression was visualized in the roots transformed with A. rhizogenes $\mathrm{K} 599$ harbouring the binary vector PCAMBIA1302 which contains GFP ORF under the control of CaMV35S promoter. A strong fluorescent signal was detected in the transformed root as shown in Fig. 4 and Additional file 2: Fig. S2. DAPI staining of transformed roots confirmed the integrity of nuclei after transformation (Fig. 5). Images of transformed roots along with untransformed as well as mock inoculated roots stained with DAPI are provided
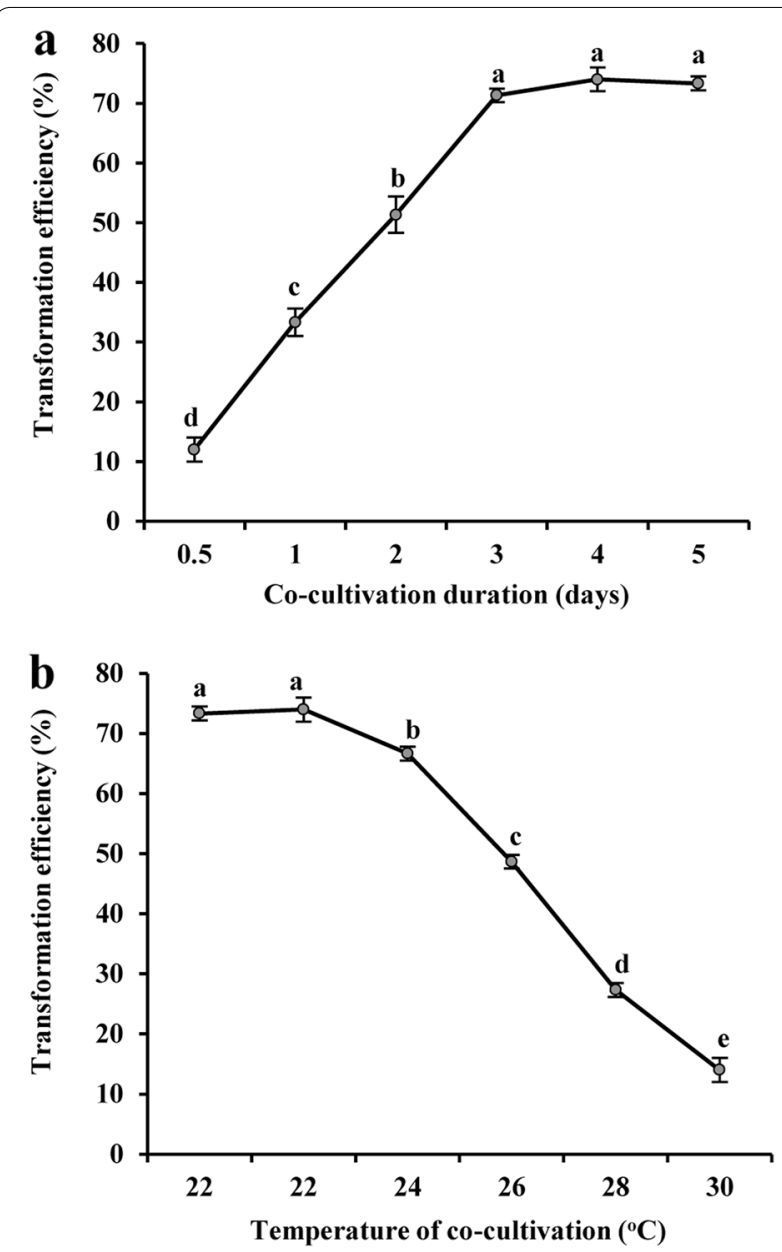

Fig. 2 Effects of co-cultivation conditions on transformation efficiency of $C$. arietinum cultivar Annigeri. a Effects of duration of co-cultivation, $\mathbf{b}$ temperature during co-cultivation on transformation frequency were determined. Each value represents the mean of three independent experiments with standard deviation (SD). Approximately 50 seedlings were examined for each individual experiment. Values with different letters are significantly different at $P<0.05$ (Fisher's LSD test)

in Additional file 2: Fig. S3. At least three replicates were used to improve the statistical significance.

\section{Determination of the transformation efficiency in different chickpea cultivars}

The transformation efficiency using $A$. rhizogenes strain K599 in different cultivars of chickpea was calculated based on both GFP expression as well as PCR confirmation to determine which chickpea cultivar is most amenable for root transformation and relevance of this protocol for future interventions during the establishment of genotype-independent transformation system. Seven chickpea cultivars namely, Annigeri, C-235, CPS 1, JG-62, K850, Vijay and WR-315 were tested in this 

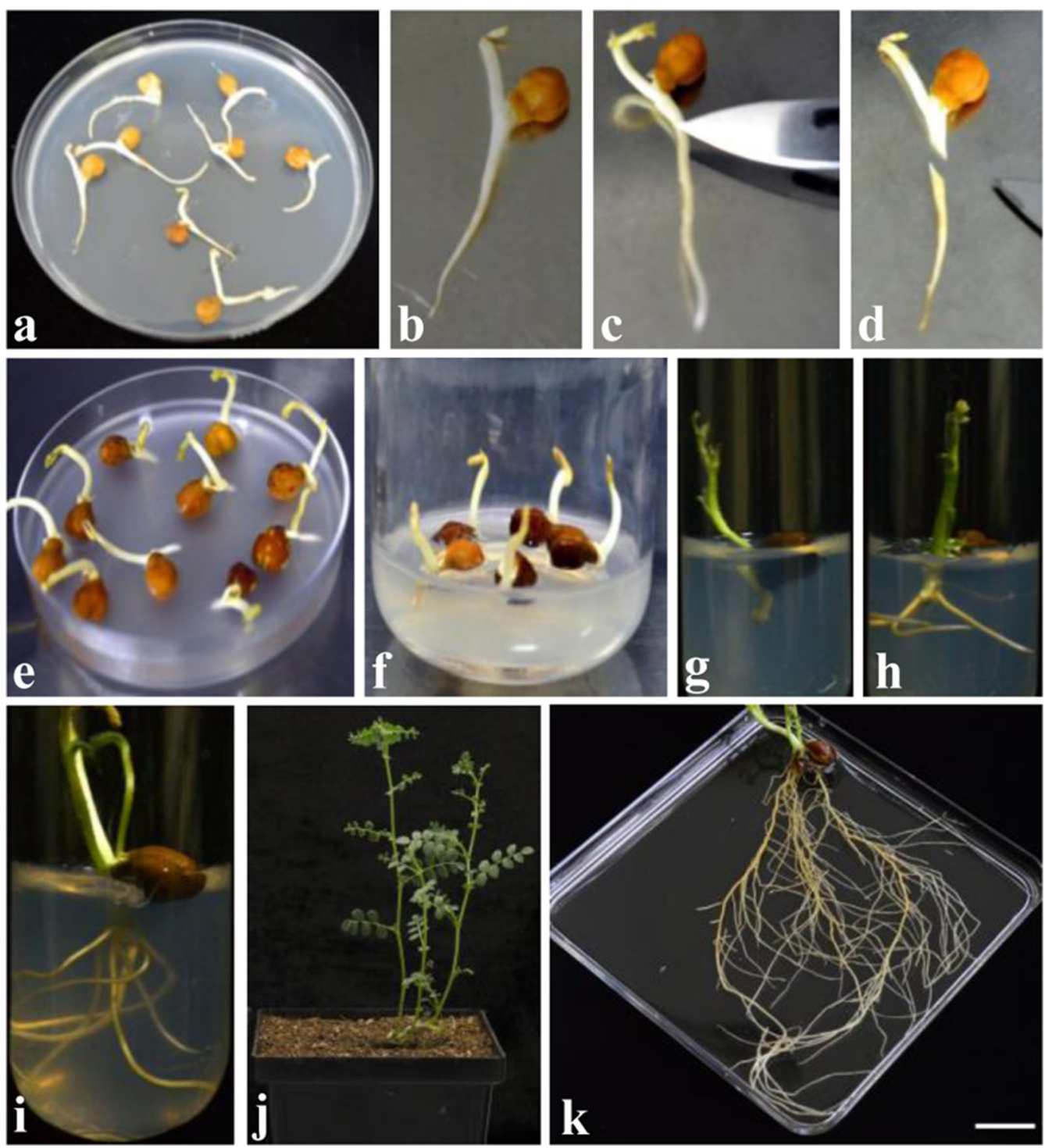

Fig. 3 Illustrations depicting the main steps for the root transformation of chickpea cultivar Annigeri. a Plants grown for 5 days in MS medium, b germinated chickpea seedling, $\mathbf{c}, \mathbf{d}$ sectioning the root near hypocotyl region, e immersing the cut end into $A$. rhizogenes suspension, $\mathbf{f}$ explant transferred in co-cultivation medium, $\mathbf{g}$ explant transferred to selection medium after co-cultivation, $\mathbf{h}, \mathbf{i}$ transformed roots grown in the selection medium after 3 and 7 days respectively. After 7 days, plantlets were transferred to pots, $\mathbf{j}$ plants grown in pot after 15 days, $\mathbf{k}$ completely grown hairy root system in chickpea. Scale bar represents $10 \mathrm{~mm}$

study. Visualization of the expression of GFP in different cultivars with untransformed as well as mock inoculated roots is given in Additional file 2: Fig. S4. Integration of transgene was confirmed by PCR analysis of genomic DNA extracted from transformed and untransformed wild-type roots. Size of the amplification product using gene specific primers was expected (642 bp) and identical to K599 strain transformed with binary vector used as a positive control (Additional file 2: Fig. S5). However, no amplification was detected in wild-type roots. Also, the amplification of $v i r D$ was not observed in any of the transformed roots suggesting the absence of Agrobacterium contamination. Based on the mean transformation efficiency, the individual chickpea cultivars were categorized into highest (above 60\%), high (between $30 \%-60 \%$ ) and low (below 30\%) transformation amenable cultivars. We observed that Annigeri and JG-62 showed highest efficiency followed by K850, CPS 1, Vijay and C-235 showing high efficiency. Lowest transformation efficiency was observed in the cultivar WR-315. The 

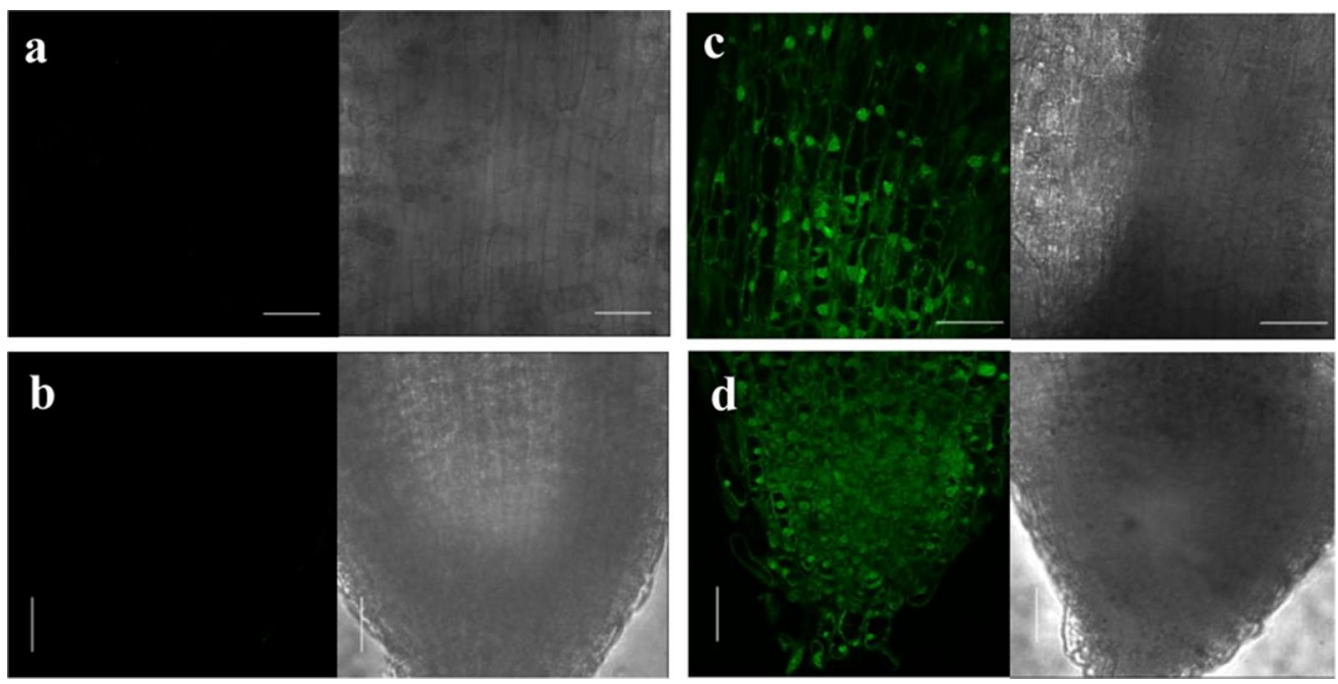

Fig. 4 Green fluorescent protein (GFP) expression in transgenic chickpea (Annigeri) roots. GFP-derived fluorescence, bright field and merged image detected by laser scanning confocal microscope in a wild-type untransformed root $(\mathbf{a}, \mathbf{b})$ and transformed hairy root $(\mathbf{c}, \mathbf{d})$. Scale bar represents $100 \mu \mathrm{m}$
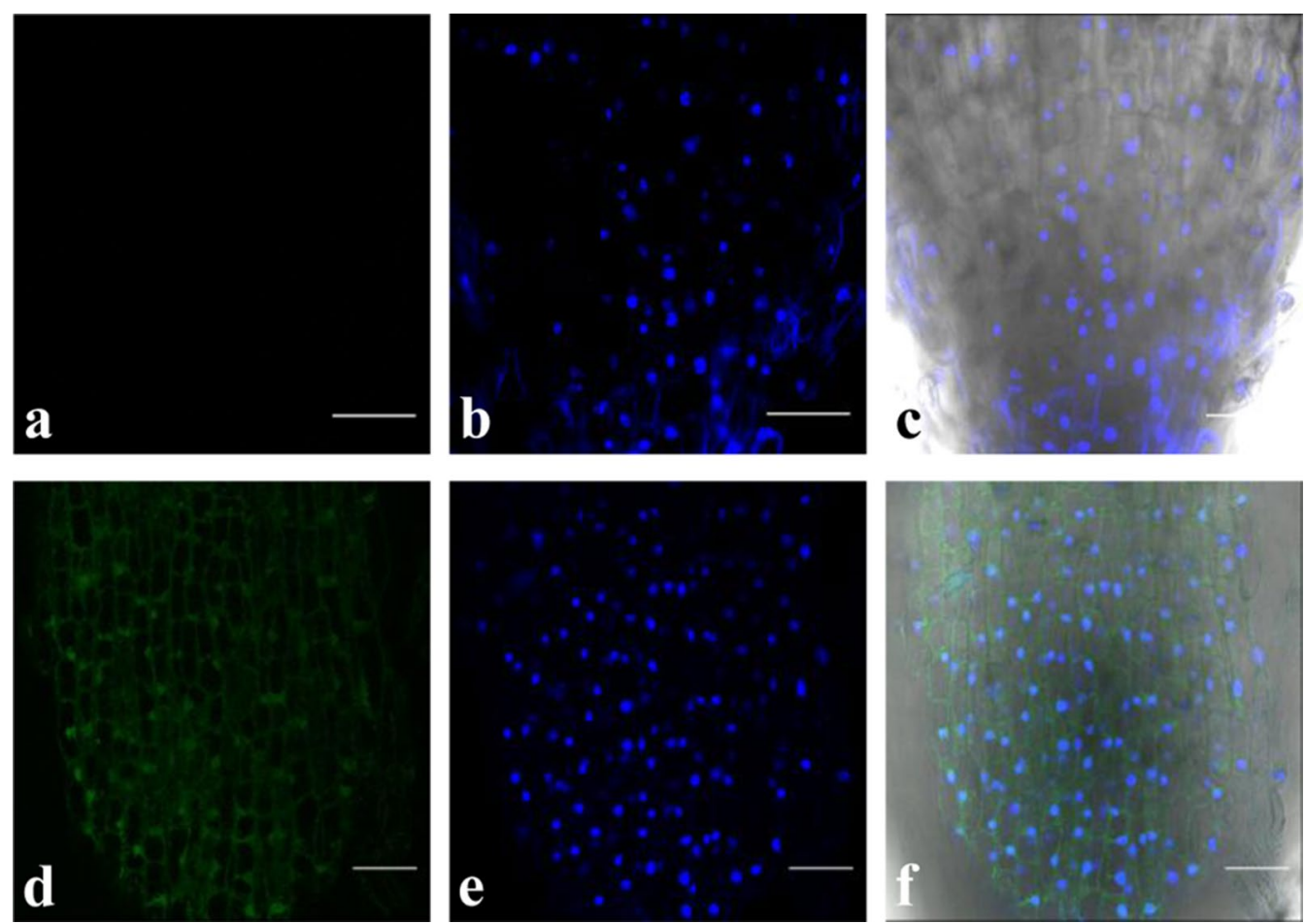

Fig. 5 Characterization of transformed roots in chickpea (Annigeri). a No GFP expression in root tip, b DAPI staining exhibiting intact nuclei, c merged image with bright field in untransformed wild-type chickpea roots. $\mathbf{d}$ Visualization of GFP expression in root tip, e DAPI staining exhibiting intact nuclei, $\mathbf{f}$ merged image with bright field in transformed chickpea roots. Scale bar represents $100 \mu \mathrm{m}$

results were reproduced from three independent experiments and the transformation efficiency of all chickpea cultivars is given in Table 3. To date, few studies have established $A$. rhizogenes-mediated root transformation in chickpea, however the efficiencies reported in these studies are very low (3-13\%). In contrast, various 
Table 3 Transformation efficiency of different chickpea cultivars. Seven chickpea cultivars inoculated with A. rhizogenes K599 strain harbouring binary vector PCAMBIA 1302

\begin{tabular}{llll}
\hline Genotype & Total number of explants inoculated & $\begin{array}{l}\text { Explants with antibiotic selection positive } \\
\text { roots (\%) }\end{array}$ & $\begin{array}{l}\text { Explants with GFP } \\
\text { positive roots (\%) }\end{array}$ \\
\hline Annigeri & & $73.50( \pm 1.32)^{\mathrm{a}^{*}}$ & $61.62( \pm 4.58)^{\mathrm{a}}$ \\
C-235 & 50 & $41.51( \pm 2.11)^{\mathrm{d}}$ & $35.58( \pm 2.67)^{\mathrm{c}}$ \\
CPS 1 & 45 & $54.25( \pm 3.14)^{\mathrm{c}}$ & $41.65( \pm 1.48)^{\mathrm{b}}$ \\
JG-62 & 40 & $72.14( \pm 3.81)^{\mathrm{a}}$ & $60.50( \pm 2.63)^{\mathrm{a}}$ \\
K850 & 49 & $54.33( \pm 0.99)^{\mathrm{c}}$ & $40.57( \pm 0.66)^{\mathrm{b}}$ \\
Vijay & 45 & $63.33( \pm 1.44)^{\mathrm{b}}$ & $44.16( \pm 1.44)^{\mathrm{b}}$ \\
WR-315 & 40 & $29.59( \pm 2.94)^{\mathrm{e}}$ & $23.51( \pm 1.81)^{\mathrm{d}}$
\end{tabular}

Each value represents the mean of three independent experiments with standard deviation (SD). Approximately $40-50$ seedlings were examined for each individual experiment

* Values in the same column followed by different letters showed significant difference among different transformation methods (Fisher's LSD test, $P<0.05$ )

** Corresponds to the frequency of seedlings that give rise to both GFP fluorescence and PCR positive roots

parameters including co-cultivation temperature and duration have been optimized in the present study to achieve high transformation efficiency (23-61\%) (Additional file 1: Table S1).

\section{Expression of AtTT2 in chickpea hairy roots and quantification of soluble PAs}

Hairy roots can serve as an important tool for reverse genetics studies and gene expression analyses $[22,55,56]$. We further extended our study to validate the applicability of this method by expressing Arabidopsis TRANSPARENT TESTA 2 (AtTT2) gene in chickpea hairy roots. AtTT2 is known to be involved in proanthocyanidins (PAs) biosynthesis [47]. PAs are oligomeric and polymeric end products of flavonoid biosynthetic pathway that play important role in plant defence, such as protection against UV light damage, mechanical wounding, insect infestation and fungal infection [57-62]. Precisely, accumulation of proanthocyanidins in barley and poplar has been shown to potentially inhibit the growth of fungal pathogens, Fusarium species and Dothiorella gregaria, respectively [63, 64]. In our study, the transgenic roots expressing TT2 showed intense blue colour after staining with DMACA, indicating the presence of PA polymers in the hairy roots (Fig. 6). Staining of whole chickpea plant expressing TT2 exhibited the development of strong blue colour in the transgenic roots without any visible chimera. However, the colour was not observed in the wildtype roots. The staining of wild-type, mock inoculated and hairy root is shown in Additional file 2: Fig. S6. Also, the PCR analysis of roots expressing AtTT2 along with the positive and negative control is provided in Fig. $6 \mathrm{f}$. Further, quantification of soluble PAs was performed, which confirmed the concomitant accumulation of high soluble PAs (approximately $1.2 \mathrm{mg}$ catechin equivalents per $g$ fresh weight) in transgenic roots, as compared to wild-type roots (Fig. 7a).

Inoculation of chickpea hairy root by Fusarium oxysporum To explore the applicability of chickpea hairy roots in studying stress response, we conducted infection assay using fungal pathogen, Fusarium oxysporum f. sp. ciceri. Previously, we have shown that this fungal strain infects chickpea [8]. Given that the accumulation of PAs led to enhanced resistance in host plants, we utilized hairy roots expressing TT2 for infection at 5 DAI (days after inoculation) and found that the fungal biomass was significantly reduced in transgenic roots, as compared to wild-type (Fig. 7b). Also, the colonization in transformed roots was visualized by staining with wheat germ agglutinin-TMR (WGA-TMR) for fungal chitin. In consistence with the quantitative data, fungal colonization was limited in the roots expressing TT2 (Fig. 7c-n).

Overall, the current method can be implemented for discerning root-rhizosphere interaction in chickpea. The contrasting differences in the tolerance/susceptibility of different cultivars further highlight the requirement of an efficient transformation protocol for a number of genotypes, which can be used further to understand the molecular mechanism underlying differential stress response in plants induced by pathogen and/or other environmental factors, such as dehydration, heat and salinity.

\section{Conclusion}

Agrobacterium rhizogenes-mediated root transformation has largely been used to analyze gene functions in various crops. Among legumes, it was first demonstrated in Lotus corniculantus which was further utilized to study root nodule development $[65,66]$. Subsequently, the 


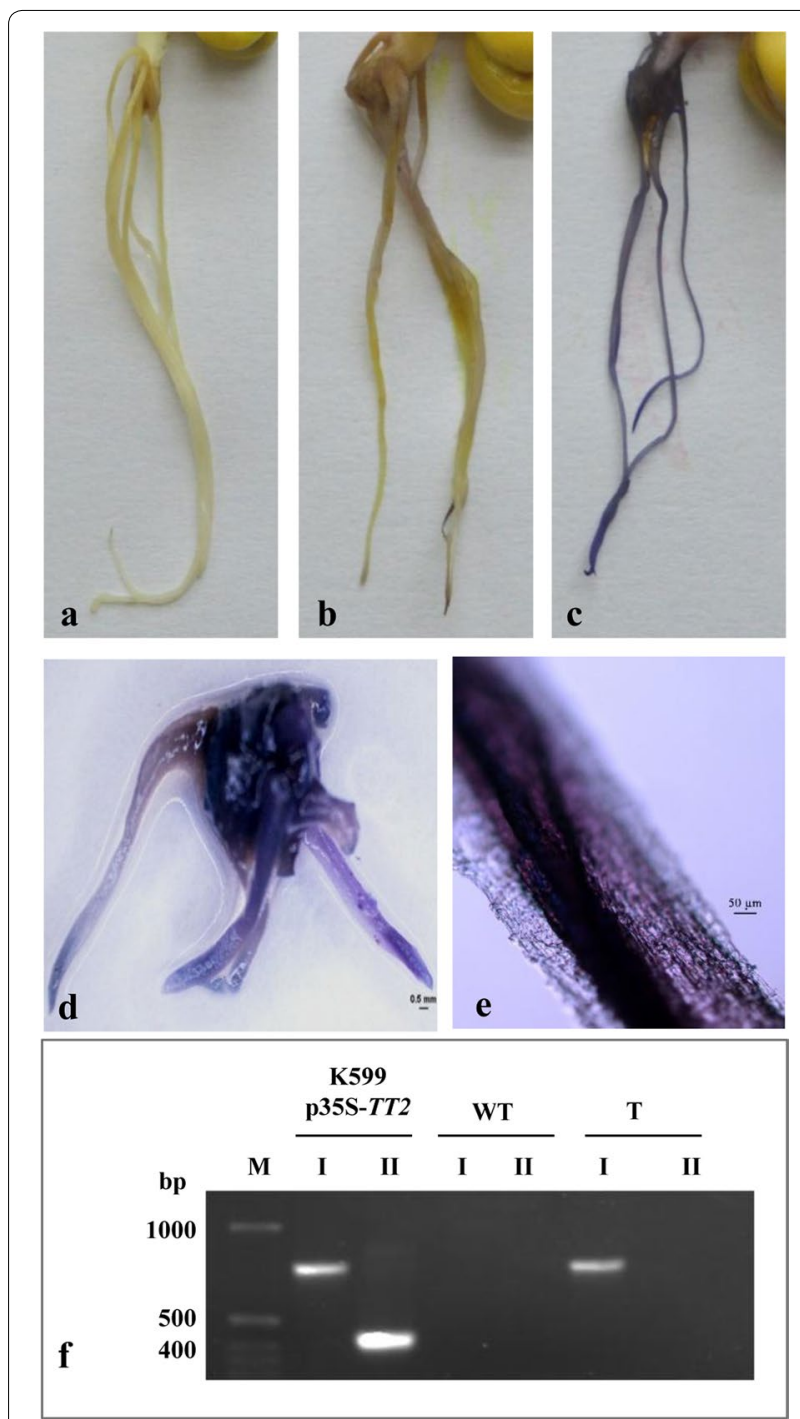

Fig. 6 PA accumulation in transgenic roots of chickpea cultivar JG-62 expressing AtTT2:GFP. a Wild-type, b mock transformed and, c-e AtTT2-transformed roots after staining with DMACA reagent, f PCR amplification of TT2 (I) and virD (II) genes in A. rhizogens K599-p35S-TT2, untransformed wild-type (WT) and transgenic roots ( $\mathrm{T}$ ) and lane $\mathrm{M}$ is a 1-kb ladder (Invitrogen). Scale bars: for $\mathbf{d} 0.5 \mathrm{~mm}$ and for e $50 \mu \mathrm{m}$

technique has been used for investigating root-microbe interactions, over-expression and knock-down of key genes for functional characterization [43]. In legumes, this method has a wide applicability as several pathogens invade the plants from roots and legumes are known for their symbiotic association with rhizosphere microbes. Among legumes, research on chickpea is gaining momentum due to its agronomic importance and being a major source of dietary protein. However, the recalcitrant nature of this crop has always been a limiting factor for genetic transformation using $A$. tumefaciens. Therefore, it is very important to develop an efficient transformation method to analyze function of biomarkers identified through various condition-dependent transcriptome and proteome studies. Here, we demonstrate an efficient, high-throughput and genotype-independent method of root transformation in chickpea using $A$. rhizogenes. The protocol described in our study provides an opportunity to transform chickpea roots in less time with high competence. This method is faster, more efficient and reproducible than the conventional transformation methods using A. tumefaciens. Use of different chickpea cultivars shows the efficacy of the method in a genotype-independent manner that makes it more amenable for largescale screening of biomarkers. Further, validation using AtTT2 gene confirmed the applicability of our method. Besides, interestingly enough, overexpression of AtTT2 enhanced the level of PAs in hairy roots, which might decrease the colonization of fungal pathogen, $F$. oxysporum. Previously, accumulation of PAs had been shown to potentially inhibit the growth of Fusarium species in barley [63]. Very recently, overexpression of $A t T T 2$ like gene $M Y B 115$ has been shown to enhance fungal resistance in poplar [64]. Altogether, this protocol offers an opportunity to functionally characterize genes involved in root developmental processes, plant-pathogen and plantmicrobe interaction as well as the interaction of root with rhizosphere and abiotic stress response.

\section{Methods \\ Chemicals}

LB agar (Invitrogen Cat. \# 22700025), LB broth (Invitrogen Cat. \# 127800520), Acetosyringone (SIGMA Cat. \# D134406), Potato dextrose broth (HIMEDIA Cat. \# M403), MS salt (SIGMA Cat. \# M5524), sucrose (SIGMA Cat. \# S0389), agar (SIGMA Cat. \# A4550), Cefotaxime (SIGMA Cat. \# 22128), Hygromycin (SIGMA Cat. \# H9773), Kanamycin (SIGMA Cat. \# K4378),

(See figure on next page.)

Fig. 7 PAs accumulation leads to decreased fungal biomass in transformed chickpea (JG-62) roots. a Levels of proanthocyanidins (PAs) in untransformed wild-type (WT) and transgenic roots ( $\mathrm{T}$ ), $\mathbf{b}$ relative fungal biomass estimation in untransformed wild-type (WT) and transgenic roots $(\mathrm{T})$. Each value represents the mean of three independent experiments with standard error (SE). Approximately 3-5 replicates were examined for each individual experiment. Statistically significant differences are indicated by an asterisk at $P<0.05$ (Fisher's LSD test). After 5 DPI, untransformed roots showing $\mathbf{c}, \mathbf{f}$ no GFP fluorescence, $\mathbf{d}$, $\mathbf{g}$ high fungal colonization, $\mathbf{e}, \mathbf{h}$ merged image of root elongation and tip zones, respectively. AtTT2:GFP transformed roots showing $\mathbf{i}$, I GFP fluorescence, $\mathbf{j}, \mathbf{m}$ less fungal colonization, $\mathbf{k}, \mathbf{n}$ merged image of root elongation and tip zones, respectively. Scale bars: $100 \mu \mathrm{m}$ 

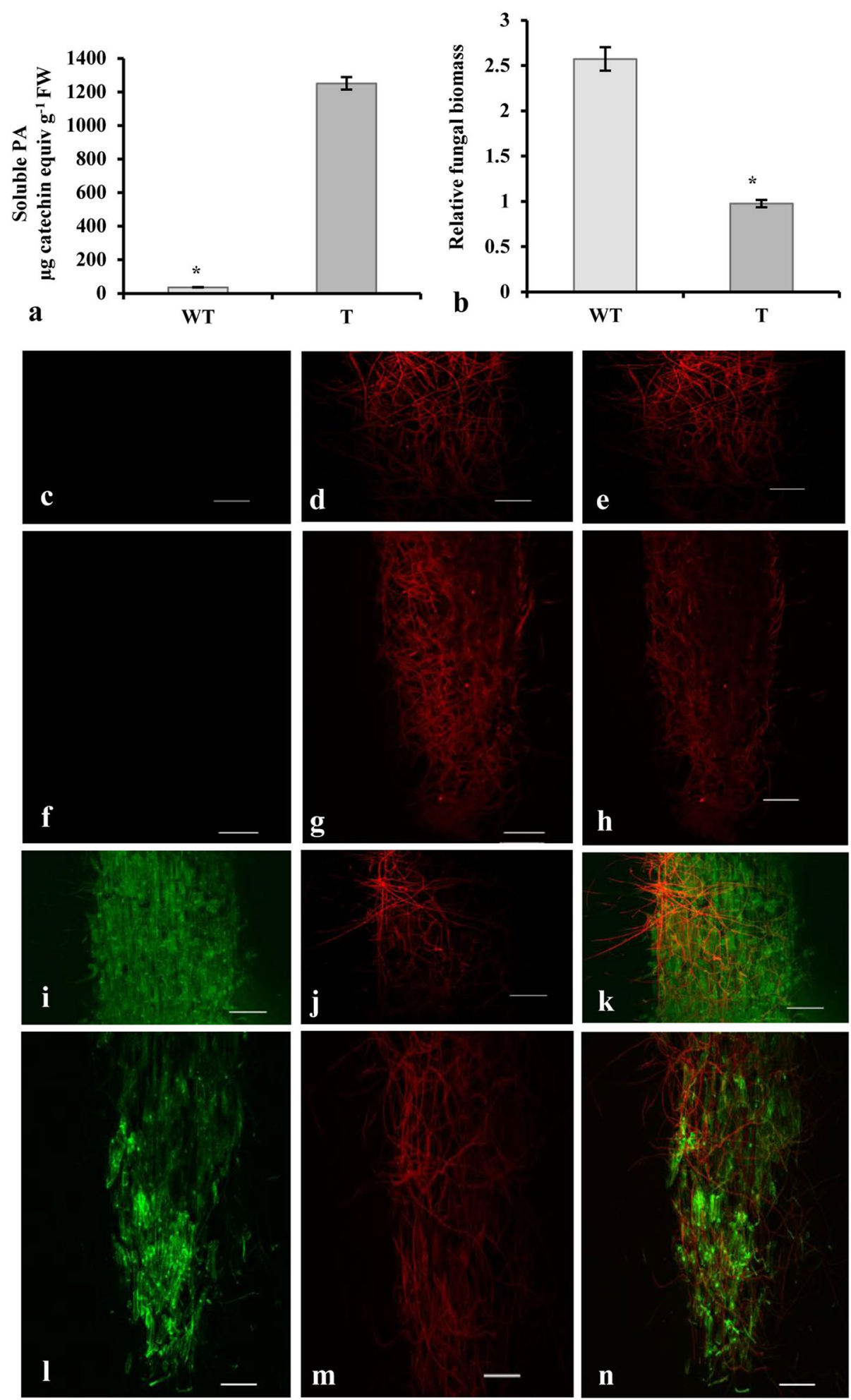
4-dimethylaminocinnamaldehyde (DMACA) (SIGMA Cat. \# D4506), catechin (SIGMA Cat. \# C1251). All other chemicals were purchased from SIGMA-Aldrich (St. Louis, MO).

\section{Agrobacterium rhizogenes strain and binary vector}

Agrobacterium rhizogenes strain $\mathrm{K} 599$ also known as NCPPB2659 was obtained from National Collection of Plant Pathogenic Bacteria Central Science Laboratory, Sand Hutton, York YO 41 ILZ England (http://www. ncppb.com). Binary vector pCAMBIA1302 (CAMBIA) which contains GFP ORF under the control of CaMV35S promoter was introduced into $A$. rhizogenes strains by electroporation. Agrobacterium strain harboring the binary vector were streaked directly from glycerol stock onto LB agar plates supplemented with kanamycin $\left(50 \mathrm{mg} \mathrm{L}^{-1}\right)$ and incubated for 2 days at $25^{\circ} \mathrm{C}$. A single colony was grown in LB broth medium containing kanamycin $\left(50 \mathrm{mg} \mathrm{L}^{-1}\right)$ and incubated at $25{ }^{\circ} \mathrm{C}$ at $180 \mathrm{rpm}$. Secondary culture was inoculated into $50 \mathrm{~mL}$ LB containing kanamycin $\left(50 \mathrm{mg} \mathrm{L}^{-1}\right)$ from $0.1 \%$ of the overnight grown culture. $50 \mu \mathrm{L}$ of $100 \mathrm{mM}$ acetosyringone was added after OD reaches to 0.6 and incubated at $25{ }^{\circ} \mathrm{C}$ for $5 \mathrm{~h}$ for inducing virulence. The culture was resuspended in sterile distilled water containing $100 \mu \mathrm{M}$ acetosyringone.

\section{Plant material and growth conditions}

Chickpea (Cicer arietinum L.) seeds used in this study were obtained from ICRISAT, Hyderabad and multiplied at the experimental fields of NIPGR, New Delhi. Seeds were sterilized with $4 \%$ sodium hypochlorite for $15 \mathrm{~min}$ followed by washing with autoclaved water for 7-8 times and soaked overnight in the dark. Seeds were placed on MS salt mixture media (SIGMA) containing 0.6\% agar (SIGMA) and incubated for 5 days in dark in the growth chamber. The temperature and humidity in growth room were maintained at $25 \pm 2{ }^{\circ} \mathrm{C}$ and $50 \pm 5 \%$ relative humidity under $16 \mathrm{~h}$ photoperiod $\left(60 \mu \mathrm{M} \mathrm{m}^{-2} \mathrm{~s}^{-1}\right)$.

\section{Explant preparation and transformation}

Five days old healthy seedlings were used for transformation by cutting the radical near the collar region using a sterile scalpel. Radicals were immersed in the suspension of $A$. rhizogenes strain $\mathrm{K} 599$ harboring control plasmid or plasmid containing the gene of interest for $35 \mathrm{~min}$ at room temperature. Seedlings were placed on the Whatman \#5 filter paper for $5 \mathrm{~s}$ and then transferred onto MS agar medium. Vials were incubated in dark for 4 days for co-cultivation at $22{ }^{\circ} \mathrm{C}$ and $70 \%$ humidity. Co-cultivation conditions were optimized by assessing the root transformation efficiencies at different temperatures $(20,22,24$, 26,28 and $\left.30^{\circ} \mathrm{C}\right)$ and co-cultivation durations $(0.5,1,2,3$,
4 and 5 days). After co-cultivation, seedlings were transferred to fresh vials containing cefotaxime $\left(250 \mathrm{mg} \mathrm{L}^{-1}\right)$, hygromycin $\left(20 \mathrm{mg} \mathrm{L}^{-1}\right)$ and incubated at $25 \pm 2{ }^{\circ} \mathrm{C}$ with a $16 \mathrm{~h}$ photoperiod $\left(60 \mu \mathrm{M} \mathrm{m}^{-2} \mathrm{~s}^{-1}\right)$. In parallel, control plants were immersed in sterile water and transferred onto the MS medium with or without antibiotic. For GFP visualization and stress treatment, transformed roots as well as the untransformed plantlets were further transferred to fresh MS medium without antibiotic or into pots containing a mixture of agropeat (Prakruthi Agro Tech, India) and vermiculite (1:1).

Alternatively, transformation by injection method was performed as described by Estrada-Navarrete et al. [40]. Briefly, five days old plantlets with unfolded cotyledons were pricked and inoculated by direct injection into the cotyledonary nodes using a sterile syringe. Approximately, 5-10 $\mu \mathrm{L}$ of the inoculum was injected into the wound for three times at different positions around the node. After inoculation, plants were transferred to the pots, kept in tray covered with a plastic lid and incubated in a growth chamber at $25{ }^{\circ} \mathrm{C}(16 \mathrm{~h} / 8 \mathrm{~h}$ light and dark photoperiod).

\section{Screening of GFP positive roots}

Ten days after inoculation or seven days after transferring the plantlets onto selection medium, roots were collected from transformed as well as control plants. Root sections were fixed and embedded following Ferguson and Reid [67] with modifications. Briefly, the samples were fixed in $4 \%(\mathrm{v} / \mathrm{v})$ formaldehyde for $2 \mathrm{~h}$ followed by dehydration in graduated series of ethanol for $3 \mathrm{~h}$. Further, the sections were treated with xylene for $5 \mathrm{~h}$ and embedded in paraffin (MERCK). Sections were prepared with a Rotary microtome (Leica). The surface area of each root was scanned for GFP visualization using confocal microscope (Leica SP2 LCM). Fluorescence signals were observed using $488 \mathrm{~nm}$ excitation and $520 \mathrm{~nm}$ emission filters.

\section{Histochemical staining of AtTT2-transformed roots and visualization}

Histochemical analysis of PA accumulation in chickpea roots transformed with $T T 2$ was performed as described by Pang et al. [68]. In brief, roots were immersed in $0.5 \%$ $(\mathrm{w} / \mathrm{v})$ DMACA in ethanol and $6 \mathrm{M} \mathrm{HCl}(1: 1, \mathrm{v} / \mathrm{v})$ for $3 \mathrm{~h}$. Images of stained roots were recorded using AZ100 stereozoom microscope (Nikon) and Eclipse 80i microscope (Nikon).

\section{DNA extraction and PCR analysis}

DNA from transformed and wild-type roots was extracted using DNeasy Plant Mini Kit (QIAGEN). The following primers were used for the amplification of 642 bp and 438 bp fragments of GFP and virD, respectively 
(GFP forward 5' GTAAACGGCCACAAGTTCAGCG 3', GFP reverse $5^{\prime}$ TCGTCCATGCCGAGAGTGATCC 3'; virD forward 5' ATGTCGCAAGGACGTAAGCCGA 3', virD reverse $5^{\prime}$ GGAGTCTTTCAGCATGGAGCAA $3^{\prime}$ ). The PCR reaction mixture was as follows: $10 \mathrm{ng}$ of plant genomic DNA, $2.5 \mu \mathrm{L}$ of $10 \times$ PCR buffer, $1.5 \mu \mathrm{L}$ of 25 $\mathrm{mM} \mathrm{MgCl} 2,1.0 \mu \mathrm{L}$ of $2.5 \mathrm{mM}$ dNTP, 1 unit of Phusion High-Fidelity DNA polymerase (Thermo Scientific), $1 \mu \mathrm{L}$ of $10 \mathrm{pM}$ forward and reverse primers in a final volume of $25 \mu \mathrm{L}$. PCR was carried out using the following cycle conditions: $98^{\circ} \mathrm{C}$ for $30 \mathrm{~s} 1$ cycle, $98^{\circ} \mathrm{C}$ for $30 \mathrm{~s}, 60^{\circ} \mathrm{C}$ for $30 \mathrm{~s}$ (for GFP) and $56{ }^{\circ} \mathrm{C}$ for $30 \mathrm{~s}$ (for virD), $72{ }^{\circ} \mathrm{C}$ for $45 \mathrm{~s}$ 30 cycles and a final extension at $72{ }^{\circ} \mathrm{C}$ for $10 \mathrm{~min}$. Amplified products were electrophoresed on $1.5 \%$ agarose gel containing $0.5 \mathrm{mg} \mathrm{L}^{-1}$ ethidium bromide and visualised under UV light.

\section{Proanthocyanidins (PAs) quantification}

Soluble PAs extraction was performed as described by Pang et al. [68]. Briefly, roots were ground in liquid nitrogen and $1 \mathrm{~g}$ of tissue was extracted with $5 \mathrm{~mL}$ of extraction solution ( $70 \%$ acetone, $0.5 \%$ acetic acid) followed by vortexing and sonication at $30{ }^{\circ} \mathrm{C}$ for $30 \mathrm{~min}$. Samples were centrifuged at $2500 \mathrm{~g}$ for $10 \mathrm{~min}$ and residues were re-extracted twice as above. Supernatants from each extraction were pooled and extracted with $30 \mathrm{~mL}$ of chloroform. Aqueous supernatant was re-extracted twice with chloroform and three times with hexane. Samples were freeze dried and resuspended in the extraction solution to a final concentration of $3 \mathrm{~g}$ of original sample $/ \mathrm{mL}$. $2.5 \mu \mathrm{L}$ aliquots of samples were mixed with $197.5 \mu \mathrm{L}$ of DMACA reagent [0.5\% (w/v) DMACA in methanol-3 N HCl (1:1)] in microwell plate. For blanks, the same samples were replaced with $2.5 \mu \mathrm{L}$ of extraction solution. Catechin was used as a standard. For samples, blanks and standards absorbance was read at $640 \mathrm{~nm}$ on a POLARstar Omega (BMG LABTECH) plate reader within $15 \mathrm{~min}$. Blanks were subtracted from samples and PA content was calculated as catechin equivalents.

\section{Fungal infection, visualization and biomass determination}

For stress treatment, fungal strain Fusarium oxysporum f. sp. ciceri race 1 was grown in $50 \mathrm{~mL}$ of potato dextrose broth (PDB) and incubated at $28{ }^{\circ} \mathrm{C}$ with $180 \mathrm{rpm}$ for 7-8 days. F. oxysporum spores were filtered using sterile cheese cloth to remove the mycelium. Number of spores were counted using hemocytometer and spore suspension was diluted to the concentration of $1 \times 10^{6}$ spores $\mathrm{mL}^{-1}$ with sterile distilled water. C. arietinum cultivar JG-62 transformed with TT2 as well as wild-type were used for infection studies. Ten days old transformed roots were dipped into $F$. oxysporum spore suspension while the control plants were treated with water. Roots were harvested at three days post infection for microscopic analysis and fungal biomass determination.

Control and transformed roots infected with $F$. oxysporum were fixed at $5 \mathrm{DAI}$ and stained with Wheat Germ Agglutinin, Tetramethylrhodamine Conjugate (Thermo Scientific, India), as described by Deshmukh et al. [69]. Briefly, root segments were fixed at room temperature for $2 \mathrm{~h}$ in $4 \%$ paraformaldehyde with $2 \mathrm{mM} \mathrm{MgCl} 2,2 \mathrm{mM}$ EGTA and $0.1 \%$ Tween $20(\mathrm{w} / \mathrm{v})$. Fixed root segments were washed with $1 \times$ PBS (phosphate buffer saline) and transferred into enzyme solution containing $10 \mathrm{mg} \mathrm{mL}^{-1}$ driselase, $10 \mathrm{mg} \mathrm{mL}^{-1}$ chitinase, $10 \mathrm{mg} \mathrm{mL}^{-1}$ proteinase $\mathrm{K}$ and $1 \mathrm{mg} \mathrm{mL}^{-1} \mathrm{BSA}$ for $15 \mathrm{~min}$ at RT. After rinsing with PBS, root segments were treated with $0.5 \%$ Triton $\mathrm{X}-100$, rinsed twice with PBS and used for subsequent staining. Screening of stained roots was done using a Leica SP2 LCM confocal microscope. Fluorescence signals were observed using $555 \mathrm{~nm}$ excitation and $580 \mathrm{~nm}$ emission filters.

The levels of $F$ oxysporum and chickpea DNA were determined using qRT-PCR with pathogen specific primers for F. oxysporum glyceraldehyde 3-phosphate dehydrogenase (GPD) forward 5'AAGGGTGCTTCTTACGAC CA $3^{\prime}$, reverse $5^{\prime}$ ATCGGAGGAGACAACATCGT $3^{\prime}$ and chickpea $18 s$ rRNA forward 5' CTCGGCCCAACTCCG GTTCG $3^{\prime}$, reverse $5^{\prime}$ CGCACGAAAACCGTCTCC GGT $3^{\prime}$. Relative fungal biomass was calculated by normalizing the Ct value of $F$. oxysporum GPD to chickpea 18 s $r$ RNA.

\section{Statistical analysis}

The data was compared by ANOVA followed by a comparison of means using Fisher's LSD test. Values followed by different letters are significantly different at $P<0.05$.

\section{Additional files}

Additional file 1. Table S1. Comparison of method and transformation efficiency with previous studies.

Additional file 2. Fig. S1. Wild-type and transformed roots of chickpea cultivar Annigeri grown in selection medium. Fig. S2. Green fluorescent protein (GFP) visualization by confocal microscopy in transformed chickpea (cultivar Annigeri) roots. Fig. S3. Characterization of transformed roots in chickpea cultivar Annigeri. Fig. S4. Green fluorescent protein (GFP) expression in different chickpea cultivars. Fig. S5. PCR analysis of transgenic chickpea roots expressing GFP. Fig. S6. Characterization of roots of chickpea cultivar JG-62 expressing AtTT2:GFP.

\section{Abbreviations}

EST: expressed sequence tags; Ti plasmid: tumor inducing plasmid; Ri plasmid: root inducing plasmid; rol: root locus; GFP: green fluorescent protein; WGA: wheat germ agglutinin; TMR: tetramethylrhodamine.

\section{Authors' contributions}

The study was conceived by SC. SC, PRA and PN designed the study. Experiments were performed by PRA, PC and PN. PRA, PN, PC, NC and SC 
contributed to data interpretation. The manuscript was written by SC, PRA and PN. All authors read and approved the final manuscript.

\section{Acknowledgements}

We thank Cambia for pCambia1302 vector and the Confocal facility, NIPGR used in this study. Authors also thank Mr. Jasbeer Singh for his assistance in preparing illustrations and graphical representations in the manuscript.

\section{Competing interests}

The authors declare that they have no competing interests.

\section{Availability of data and materials}

All the data is contained within the manuscript.

\section{Consent for publication}

Not applicable.

\section{Ethics approval and consent to participate}

Not applicable.

\section{Funding}

This work was supported by grants from the Department of Biotechnology (DBT) (BT/HRD/35/01/05/2013 and BT/AGR/CG-Phasell/01/2014), Government of India and the National Institute of Plant Genome Research, New Delhi, India to S. C. P.R.A. is the recipient of pre-doctoral fellowship from the Council of Scientific and Industrial research (CSIR), Govt. of India. P.C. is the recipient of pre-doctoral fellowship from the University Grant Commission (UGC), Govt. of India.

\section{Publisher's Note}

Springer Nature remains neutral with regard to jurisdictional claims in published maps and institutional affiliations.

\section{Received: 4 July 2017 Accepted: 2 June 2018}

Published online: 06 July 2018

\section{References}

1. Graham PH, Vance CP. Legumes: importance and constraints to greater use. Plant Physiol. 2003;131:872-7.

2. United Nations General Assembly Resolution 231, Session 68, 2013.

3. Varshney RK, Song C, Saxena RK, Azam S, Yu S, Sharpe AG, et al. Draft genome sequence of chickpea (Cicer arietinum) provides a resource for trait improvement. Nat Biotechnol. 2013:31:240-6.

4. FAO. Food and Agricultural Organization of the United Nation. 2014. FAO Statistical Database. http://faostat.fao.org. Accessed 30 June 2017.

5. Croser JS, Clarke HJ, Siddique KHM, Khan TN. Low-temperature stress: implications for chickpea (Cicer arietinum L.) improvement. Crit Rev Plant Sci. 2003;22:185-219.

6. Singh KB, Malhotra RS, Halila MH, Knights EJ, Verma MM. Current status and future strategy in breeding chickpea for resistance to biotic and abiotic stresses. Euphytica. 1994;73:137-49.

7. Varshney RK, Close TJ, Singh NK, Hoisington DA, Cook DR. Orphan legumes enter the genomics era. Curr Opin Plant Biol. 2009;12:202-10.

8. Ashraf N, Ghai D, Barman P, Basu S, Gangisetty N, Mandal MK, et al. Comparative analyses of genotype dependent expressed sequence tags and stress-responsive transcriptome of chickpea wilt illustrate predicted and unexpected genes and novel regulators of plant immunity. BMC Genom. 2009;10:415.

9. Deokar AA, Kondawar V, Jain PK, Karuppayil SM, Raju NL, Vadez V, et al. Comparative analysis of expressed sequence tags (ESTs) between drought-tolerant and susceptible genotypes of chickpea under terminal drought stress. BMC Plant Biol. 2011;11:70.

10. Afonso-Grunz F, Molina C, Hoffmeier K, Rycak L, Kudapa H, Varshney RK, et al. Genome-based analysis of the transcriptome from mature chickpea root nodules. Front Plant Sci. 2014:5:325.

11. Garg R, Shankar R, Thakkar B, Kudapa H, Krishnamurthy L, Mantri N, et al. Transcriptome analyses reveal genotype- and developmental stage-specific molecular responses to drought and salinity stresses in chickpea. Sci Rep. 2016;6:19228.

12. Singh VK, Jain M. Transcriptome profiling for discovery of genes involved in shoot apical meristem and flower development. Genomics Data. 2014;2:135-8.

13. Jain M, Misra G, Patel RK, Priya P, Jhanwar S, Khan AW, et al. A draft genome sequence of the pulse crop chickpea (Cicer arietinum L.). Plant J. 2013;74:715-29.

14. Chakraborty S, Salekdeh GH, Yang P, Woo SH, Chin CF, Gehring C, et al. Proteomics of important food crops in the Asia Oceania Region: current status and future perspectives. J Proteome Res. 2015;14:2723-44.

15. Jaiswal DK, Ray D, Subba P, Mishra P, Gayali S, Datta A, et al. Proteomic analysis reveals the diversity and complexity of membrane proteins in chickpea (Cicer arietinum L.). Proteome Sci. 2012;10:59.

16. Subba P, Barua P, Kumar R, Datta A, Soni K, Chakraborty S, et al. Phosphoproteomic dynamics of chickpea (Cicer arietinum L.) reveals shared and distinct components of dehydration response. J Proteome Res. 2013;12:5025-47.

17. Acharjee S, Sarmah BK, Kumar PA, Olsen K, Mahon R, Moar WJ, et al. Transgenic chickpeas (Cicer arietinum L.) expressing a sequence-modified cry2Aa gene. Plant Sci. 2010;178:333-9.

18. Indurker S, Misra HS, Eapen S. Agrobacterium-mediated transformation in chickpea (Cicer arietinum L.) with an insecticidal protein gene: optimisation of different factors. Physiol Mol Biol Plants. 2010;16:273-84.

19. Mehrotra M, Singh AK, Sanyal I, Altosaar I, Amla DV. Pyramiding of modified $c r y 1 A b$ and $c r y 1 A c$ genes of Bacillus thuringiensis in transgenic chickpea (Cicer arietinum L.) for improved resistance to pod borer insect Helicoverpa armigera. Euphytica. 2011;182:87-102.

20. Patil G, Deokar A, Jain PK, Thengane RJ, Srinivasan R. Development of a phosphomannose isomerase-based Agrobacterium-mediated transformation system for chickpea (Cicer arietinum L.). Plant Cell Rep. 2009;28:1669-76.

21. Tripathi L, Singh AK, Singh S, Singh R, Chaudhary S, Sanyal I, et al. Optimization of regeneration and Agrobacterium-mediated transformation of immature cotyledons of chickpea (Cicer arietinum L.). Plant Cell Tiss Organ Cult. 2013;113:513-27.

22. lantcheva A, Mysore KS, Ratet P. Transformation of leguminous plants to study symbiotic interactions. Int J Dev Biol. 2013;57:577-86.

23. Limpens E, Ramos J, Franken C, Raz V, Compaan B, Franssen H, et al. RNA interference in Agrobacterium rhizogenes-transformed roots of Arabidopsis and Medicago truncatula. J Exp Bot. 2004;55:983-92.

24. Bercetche J, Chiriqui D, Adam S, David C. Morphogenetic and cellular reorientations induced by Agrobacterium rhizogenes (strains 1855, 2659 and 8196) on carrot, pea and tobacco. Plant Sci. 1987;52:195-210.

25. Mankin SL, Hill DS, Olhoft PM, Toren E, Wenck AR, Nea L, et al. Disarming and sequencing of Agrobacterium rhizogenes strain K599 (NCPPB2659) plasmid pRi2659. In Vitro Cell Dev Biol Plant. 2007;43:521.

26. David C, Chilton MD, Tempe J. Conservation of T-DNA in plants regenerated from hairy root cultures. Nat Biotechnol. 1984;2:73-6.

27. Otani M, Mu M, Handa T, Kamada H, Shimada T. Transformation of sweet potato (Ipomoea batatus (L.) Lam.) plants by Agrobacterium rhizogenes. Plant Sci. 1993;94:151-9.

28. Christey MC, Sinclair BK, Braun $\mathrm{RH}$, Wyke L. Regeneration of transgenic vegetable brassicas (Brassica oleracea and B. campestris) via Ri-mediated transformation. Plant Cell Rep. 1997;16:587-93.

29. Ishizaki T, Hoshino Y, Masuda K, Oosawa K. Explants of Ri-transformed hairy roots of spinach can develop embryogenic calli in the absence of gibberellic acid, an essential growth regulator for induction of embryogenesis from non-transformed roots. Plant Sci. 2002;163:223-31.

30. Boisson-Dernier A, Chabaud M, Garcia F, Becard G, Rosenberg C, Barker DG. Agrobacterium rhizogenes-transformed roots of Medicago truncatula for the study of nitrogen-fixing and endomycorrhizal symbiotic associations. Mol Plant Microbe Interact. 2001;14:695-700.

31. Taylor CG, Fuchs B, Collier R, Lutke KW. Generation of composite plant using Agrobacterium rhizogenes. Methods Mol Biol. 2006;343:155-67.

32. Runo S, Macharia S, Alakonya A, Machuka J, Sinha N, Scholes J. Striga parasitizes transgenic hairy roots of Zea mays and provides a tool for studying plant-plant interactions. Plant Methods. 2012;8:20.

33. Lozovaya W, Lygin AV, Zernova OV, Li S, Hartman GL, Widholm JM. Isoflavonoid accumulation in soybean hairy roots upon treatment with Fusarium solani. Plant Physiol Biochem. 2004;42:671-9. 
34. Cho HJ, Farrand SK, Noel GR, Widholm JM. High-efficiency induction of soybean hairy roots and propagation of the soybean cystnematode. Planta. 2000;210:195-204.

35. Savka MA, Ravillion B, Noel GR, Farrand SK. Induction of hairy roots on cultivated soybean genotypes and their use to propagate the soybean cyst nematode. Phytopathology. 1990;80:503-8.

36. Mugnier J, Mosse B. Vesicular-arbuscular mycorrhizal infection in transformed root-inducing T-DNA roots grown axenically. Phytopathology. 1987:77:1045-50

37. Nuutila AM, Vestberg M, Kauppinen V. Infection of hairy roots of strawberry (Fragaria $\times$ Ananassa Duch) with arbuscular mycorrhizal fungus. Plant Cell Rep. 1995;14:505-9.

38. Huo X, Schnabel E, Hughes K, Frugoli J. RNAi Phenotypes and the localization of a Protein:GUS fusion imply a role for Medicago truncatula PIN genes in nodulation. J Plant Growth Regul. 2006;25:156-65.

39. Kuppusamy KT, Ivashuta S, Bucciarelli B, Vance CP, Gantt JS, Vander-bosch KA. Knockdown of CELL DIVISION CYCLE16 reveals an inverse relationship between lateral root and nodule numbers and a link to auxin in Medicago truncatula. Plant Physiol. 2009;151:1155-66.

40. Estrada-navarrete G, Alvarado-affantranger X, Olivares JE, diaz-camino C Santana O, Murillo E, et al. Agrobacterium rhizogenes-transformation of the Phaseolus spp.: a tool for functional genomics. Mol Plant Microbe Interact. 2006;19:1385-93.

41. Clemow SR, Clairmont L, Madsen LH, Guinel FC. Reproducible hairy root transformation and spot-inoculation methods to study root symbioses of pea. Plant Methods. 2011;7:46.

42. Hakoyama T, Niimi K, Yamamoto T, Isobe S, Sato S, Nakamura Y, et al. The integral membrane protein SEN1 is required for sym-biotic nitrogen fixation in Lotus japonicus nodules. Plant Cell Physiol. 2012;53:225-36.

43. Saito K, Yoshikawa M, Yano K, Miwa H, Uchida H, Asamizu E, et al. NUCLEO-PORIN85 is required for calcium spiking, fungal and bacterial symbioses, and seed production in Lotus japonicus. Plant Cell. 2007;19:610-24.

44. Crane C, Wright E, Dixon RA, Wang ZY. Transgenic Medicago truncatula plants obtained from Agrobacterium tumefaciens-transformed root and Agrobacterium rhizogenes-transformed hairy roots. Planta. 2006;223:1344-54.

45. Bajrovic K, Gozukirmizi N. Regeneration and hairy root formation of chickpea using callus derived plantlets and seedlings. Intl Chickpea and Pigeonpea Newslett. 1997:4:30-1.

46. Khawar KM, Ozcan S. Hairy root transformation in turkish chickpea (Cicer arietinum L) cultivars. Biotechnol Biotechnol Equip. 2004;3:51-4.

47. Nesi N, Jond C, Debeaujon I, Caboche M, Lepiniecm L. The Arabidopsis TT2 gene encodes an R2R3 MYB domain protein that acts as a key determinant for proanthocyanidin accumulation in developing seed. Plant Cell. 2001;13:2099-114.

48. McCormac AC, Elliott MC, Chen DF. A simple method for the production of highly competent cells of Agrobacterium for transformation via electroporation. Mol Biotechnol. 1998:9:155-9.

49. Estrada-Navarrete G, Alvarado-Affantranger X, Olivares JE, Guillen G, Diaz-Camino C, Campos F, et al. Fast, efficient and reproducible genetic transformation of Phaseolus spp. by Agrobacterium rhizogenes. Nat Protoc. 2007:2:1819-24.

50. Ishida Y, Hiei Y, Komari T. Agrobacterium-mediated transformation of maize. Nat Protoc. 2007:2:1614-21.
51. Alpizar E, Dechamp E, Espeout S, Royer M, Lecouls AC, Nicole M, et al. Efficient production of Agrobacterium rhizogenes-transformed roots and composite plants for studying gene expression in coffee roots. Plant Cell Rep. 2006;25:959-67.

52. Boisson-Dernier A, Chabaud M, Garcia F, Bécard G, Rosenberg C, Barker DG. Agrobacterium rhizogenes-transformed roots of Medicago truncatula for the study of nitrogen-fixing and endomycorrhizal symbiotic associations. Mol Plant Microbe Interact. 2001;14:695-700.

53. Leroy T, Henry AM, Royer M, Altosaar I, Frutos R, Duris D, et al. Genetically modified coffee plants expressing the Bacillus thuringiensis crylAc gene for resistance to leaf miner. Plant Cell Rep. 2000;19:382-9.

54. Jian B, Hou W, Wu C, Liu B, Liu W, Song S, et al. Agrobacterium rhizogenesmediated transformation of Superroot-derived Lotus corniculatus plants: a valuable tool for functional genomics. BMC Plant Biol. 2009;9:78.

55. Collier R, Fuchs B, Walter N, Kevin Lutke W, Taylor CG. Ex vitro composite plants: an inexpensive, rapid method for root biology. Plant J. 2005;43:449-57.

56. Mei WY, Wang JB, Luo D, Jia JF. Regeneration of plants from callus cultures of roots induced by Agrobacterium rhizogenes on Alhagi pseudoalhagi. Cell Res. 2001:11:279-84.

57. Shirley BW, Kubasek WL, Storz G, Bruggemann E, Koornneef M, Ausubel FM, et al. Analysis of Arabidopsis mutants deficient in flavonoid biosynthesis. Plant J. 1995:8:659-71.

58. Weisshaar B, Jenkins Gl. Phenylpropanoid biosynthesis and its regulation. Curr Opin Plant Biol. 1998;1:251-7.

59. Harborne JB, Williams CA. Advances in flavonoid research since 1992. Phytochemistry. 2000;55:481-504.

60. Pietta PG. Flavonoids as antioxidants. J Nat Prod. 2000;63:1035-42.

61. Winkel-Shirley B. Flavonoid biosynthesis. A colorful model for genetics, biochemistry, cell biology, and biotechnology. Plant Physiol. 2001;126:485-93.

62. Barbehenn RV, Peter Constabel C. Tannins in plant-herbivore interactions. Phytochemistry. 2011;72:1551-65.

63. Skadhauge B, Thomsen KK, Wettstein DV. The role of the barley testa layer and its flavonoid content in resistance to Fusarium infections. Hereditas. 1997:126:147-60.

64. Wang L, Ran L, Hou Y, Tian Q, Li C, Liu R, et al. The transcription factor MYB115 contributes to the regulation of proanthocyanidin biosynthesis and enhances fungal resistance in poplar. New Phytol. 2017;215:351-67.

65. Jensen JS, Marcker KA, Otten L, Schell J. Nodule-specific expression of a chiamaeric soybean leghaemoglobin gene in transgenic Lotus corniculatus. Nature. 1986;321:669-74.

66. Petit A, David C, Dahl GA, Ellis JG, Guyon P, Casse-Delbart F, et al. Further extension of the opine concept: plasmids in Agrobacterium rhizogenes cooperate for opine degration. Mol Gen Genet. 1983;190:204-14.

67. Ferguson BJ, Reid JB. Cochleata: getting to the root of legume nodules. Plant Cell Physiol. 2005;46:1583-9.

68. Pang Y, Peel GJ, Wright E, Wang Z, Dixon RA. Early steps in proanthocyanidin biosynthesis in the model legume Medicago truncatula. Plant Physiol. 2007; 145:601-15.

69. Deshmukh S, Huckelhoven R, Schafer P, Imani J, Sharma M, Wei M, et al. The root endophytic fungus Piriformospora indica requires host cell death for proliferation during mutualistic symbiosis with barley. Proc Natl Acad Sci USA. 2006;103:18450-7. 